\title{
Relações entre a parentalidade e a personalidade de pais e mães: uma revisão integrativa da literatura
}

\section{Las relaciones entre la parentalidad y la personalidad de los padres: una revisión integrativa de la literatura}

\section{Relations between parenting and parents personality: a integrative review of the literature}

\author{
Maria Luiza I usten da Silva* \\ Universidade Federal de Santa Catarina, Florianópolis, Santa Catarina, Brasil \\ Mauro Luís Vieira** \\ Universidade Federal de Santa Catarina, Florianópolis, Santa Catarina, Brasil
}

\begin{abstract}
RESUMO
As atividades exercidas pelas figuras parentais, que visam a sobrevivência e o desenvolvimento dos filhos, sofrem interferência de diferentes determinantes, entre eles a personalidade parental. Investigar essa relação pode contribuir com informações sobre as características individuais mais propensas a fornecer os cuidados e aquelas associadas a fatores de risco. $O$ objetivo desse artigo foi revisar os resultados de estudos sobre personalidade parental e parentalidade. A busca foi realizada nas bases de dados Capes Periódicos, PubMed e BVS-Psi com os descritores "parenting" e "parental personality. Foram encontrados 137 estudos e 18 satisfizeram os critérios de inclusão. Encontrou-se apenas estudos internacionais e verificouse que há uma tendência de os estudos utilizarem o termo "parental personality" sem diferenciar nos resultados os aspectos relacionados ao pai e à mãe. O modelo teórico predominante foi o Cinco grandes fatores da personalidade. As dimensões da personalidade extroversão e amabilidade se relacionaram à uma parentalidade calorosa e responsiva; o neuroticismo à rigidez ou permissividade; a abertura à experiência à flexibilidade; e a conscienciosidade à imposição de limites na educação. Concluiu-se que as características de personalidade de pais e mães podem ressoar em diferentes comportamentos em relação à parentalidade. Recomenda-se para pesquisas futuras a investigação de aspectos relacionados apenas ao pai e à mãe, que diferenciem o tipo de interação pais-filhos em relação ao gênero da criança.
\end{abstract}

Palavras-chave: parentalidade, personalidade, Big Five, desenvolvimento.

\section{RESUMEN}

Las actividades ejercidas por las figuras parentales orientadas a la supervivencia y el desarrollo de los hijos sufren interferencias de diferentes determinantes, entre ellos, la personalidad de los padres. Investigar esa relación puede contribuir con informaciones sobre las características individuales más propensas a fortalecer los cuidados y aquellas asociadas a 
los factores de riesgo. El objetivo de este artículo fue examinar los resultados de estudios sobre personalidad parental y parentalidad. La búsqueda fue realizada en las bases de datos Capes Periódicos, PubMed e BVS-Psi con los descriptores "parenting" e "parental personality". Fueron encontrados 137 estudios y apenas 18 satisficieron los criterios de inclusión. Se encontraron apenas estudios internacionales e se corroboró que hay una tendencia a usar la categoría "parental personality" sin que los resultados diferencien los aspectos relacionados con las madres o los padres. El modelo teórico predominante fue el de los cinco grandes factores de la personalidad. Las dimensiones de la personalidad extroversión y amabilidad se relacionaron con una parentalidad cálida y responsable; el neuroticismo a la rigidez o permisividad; la apertura a la experiencia y a la flexibilidad; y la responsabilidad a la imposición de límites en la educación. Se concluyó que las características de personalidad de padres y madres pueden repercutir en diferentes comportamientos en relación con la parentalidad. Se recomienda a investigaciones futuras el estudio de aspectos circunscritos al padre y a la madre, que distingan el tipo de interacción padres-hijos, de acuerdo con el género del niño.

Palabras-clave: parentalidad, personalidad, Cinco grandes factores, desarrollo.

\begin{abstract}
The activities carried out by parental that aim at the survival and the development of the children suffer interference from different factors, between them the parental personality. Investigating this relationship may contribute with information about the individual characteristics that are most likely to provide care and those associated with risk factors. The objective of this article was to review the results of studies about parental personality and parenting. The search was performed in Capes Periódicos, PubMed and BVS-Psi databases with the keywords: "parenting" and "parental personality". Among the 137 studies found, 18 have met the inclusion criteria. It has been found only international papers and it was noted a trend to use the term "parental personality" was shown, without differentiating the aspects related to the father and the mother in the results. The predominant theoretical model was the Big Five Factor Model. The personality dimensions of extroversion and amability were related to warm and responsive parenting; neuroticism to stiffness or permissiveness; openness to experience to flexibility; and conscientiousness to the imposition of limits in education. It was concluded that the personality characteristics of fathers and mothers can have repercussions on different behaviors in relation to parenthood. It is recommended for future research the investigation of aspects related only to the father and the mother that differentiate the type of interaction parents-children with respect to the gender of the child.
\end{abstract}

Keywords: parenting, personality, Big Five, development.

\title{
1 I ntrodução
}

As características de personalidade permeiam o comportamento das pessoas de diferentes maneiras. Elas podem moldar a forma como o indivíduo experimenta e responde a uma variedade de tarefas desenvolvimentais, tais como a participação nas relações sociais, (Roberts, Kuncel, Shiner, Caspi, \& Goldberg, 2007), a capacidade de 
liderança (Hendricks \& Payne, 2007) e a forma com podem exercer a parentalidade (Prinzie, Stams, Deković, Reijntjes, \& Belsky, 2009).

A parentalidade refere-se ao conjunto de atividades propositas pelas figuras parentais ou substitutas que visam assegurar a sobrevivência e o desenvolvimento da criança, num ambiente seguro, com o objetivo de socializá-la e torná-la gradativamente mais autônoma (Hoghughi, 2004). Esse autor, baseado nas propostas de Bronfenbrenner (1979) e Belsky (1984), preconiza a existência de onze dimensões da parentalidade que estão organizadas em Atividades parentais, Áreas funcionais e Pré-requisitos. As Atividades parentais envolvem atitudes que visam o cuidado físico, social e emocional, a disciplina e o desenvolvimento da criança. Os cuidados físicos compreendem atitudes que promovem a segurança, proteção, alimentação, entre outros. Os cuidados emocionais integram comportamentos que asseguram o respeito à criança e que propiciem oportunidades para que ela possa gerir seus riscos e fazer suas próprias escolhas. O cuidado social está relacionado a promoção de competências sociais; a disciplina à imposição de limites e o desenvolvimento está intrínseco em todas as atividades e naquelas que visam o encorajamento e exploração de novas oportunidades (Hoghughi, 2004).

As Áreas funcionais englobam aspectos do funcionamento da criança, tais como a saúde física, o funcionamento intelectual (aquisição de competências educacionais), o comportamento social e a saúde mental (pensamentos, sentimentos e comportamentos). E os Prérequisitos se referem às características e habilidades necessárias para o desenvolvimento da atividade parental, no qual se incluem o conhecimento e compreensão das necessidades da criança; a motivação, os recursos, os traços de personalidade, as redes sociais e as oportunidades que são, por exemplo, o tempo que os pais passam com os filhos (Hoghughi, 2004). Dessa forma, observa-se uma complexidade envolvida no exercício da parentalidade e sua importância para o desenvolvimento infantil.

Vários fatores condicionam e podem prejudicar os comportamentos parentais. Compreender porque é que certos indivíduos parecem ser mais adequados na realização efetiva da parentalidade enquanto outros têm maiores dificuldades é uma questão que tem implicações a nível de intervenção e prevenção. Isso permeou os estudos de Belsky (1984) ao analisar os processos parentais que ocorrem nas situações de maus tratos e abuso infantil. Por meio de uma abordagem ecológica, Belsky e Jaffee (2006) destacaram três determinantes que podem influenciar as práticas parentais: as características individuais dos pais (personalidade e psicopatologia), as características da criança (temperamento) e os fatores do contexto social no qual a relação pais-criança está inserida (relações maritais, ocupação profissional parental, redes de suporte social). 
Esse modelo considera que as histórias desenvolvimentais dos pais, o seu relacionamento conjugal e a sua posição profissional influenciam as suas personalidades, que, por sua vez, afetam o processo de parentalidade e este, consequentemente, produz efeitos no desenvolvimento infantil. Do mesmo modo, o funcionamento psicológico parental, promovido em parte pela sua história desenvolvimental, influencia direta e indiretamente a relação conjugal, o funcionamento das redes sociais e as próprias experiências ocupacionais. E a nível social e contextual, a vizinhança e a comunidade também interferem na parentalidade (Belsky \& Jaffee, 2006).

Os autores destacam que os três determinantes não possuem 0 mesmo peso na eficácia da parentalidade. A personalidade parental é considerada o determinante crucial, pois ela afeta o modo como os pais geralmente se sentem (a propensão para ter humor positivo ou negativo), como pensam e os tipos de pensamento (atribuições aos comportamentos dos filhos) e a forma de agir (como por exemplo, o grau de expressividade, de ansiedade e insegurança expressos na relação com os filhos) (Beslky, 1984; Morse, 2010).

Pesquisas sobre a personalidade têm aumentado nas duas últimas décadas (Caspi, Roberts, \& Shiner, 2005; John \& Srivastava, 1999; Prinzie et al., 2009) em busca de um consenso acerca de um modelo que abarque a infinidade de traços da personalidade. Entre os modelos mais conhecidos e respaldados está o modelo dos Cinco Grandes Fatores da Personalidade (Big Five) (DeYoung, Quilty, \& Peterson, 2007; McCrae \& Costa, 1999; Natividade \& Hutz, 2015), o qual enfatiza cinco grandes dimensões que abrangem disposições mais específicas. Os cinco fatores são tradicionalmente numerados e rotulados como: (I) Extroversão (energia, impulsividade, afeto positivo), (II) Amabilidade (sociável, amável, prestativo), (III) Conscienciosidade (restrição), (IV) Estabilidade Emocional (versus Neuroticismo ou afeto negativo), (V) Abertura à experiência (autonomia, intelecto, curiosidade e imaginação) (McCrae \& John, 1992; McCrae \& Costa, 1999).

O modelo dos determinantes da parentalidade alude ao fato de que certos fatores da personalidade dos pais facilitam a parentalidade, salientando, por exemplo, que um progenitor que apresente poucos traços de neuroticismo, índices elevados de extroversão e amabilidade, abertura à experiência e conscienciosidade, poderá providenciar um padrão educativo de maior suporte, responsividade e estimulação intelectual aos filhos (Belsky \& Jaffee, 2006).

Os estudos que investigam a relação entre personalidade de pais e mães e parentalidade tendem a dar mais ênfase à personalidade da mãe (Metsäpelto, 2003), em virtude desta continuar sendo a principal responsável pelo cuidado das crianças e das tarefas da casa (Bossardi, 2011; Staudt \& Wagner, 2008). No entanto, o interesse 
pelo estudo do papel do pai no contexto familiar e no desenvolvimento infantil aumentou nas últimas décadas (Bandeira, Goetz, Vieira, \& Pontes, 2005; Silva \& Piccinini, 2007), o que pode estar relacionado a mudanças ocorridas nas configurações familiares (Goetz \& Vieira, 2009; Wagner, Predebon, Mosmann, \& Verza, 2005). Dessa forma, salienta-se a importância de se investigar a personalidade paterna e sua possível influência na forma como o pai participa nos cuidados dos filhos e nas tarefas domésticas.

Verifica-se, por meio de uma pesquisa exploratória, o uso do termo personality e parental personality nos resumos e títulos das pesquisas que buscaram investigar a personalidade de pai e mães. Observa-se que os resultados descritos nos resumos não diferenciam as práticas parentais de acordo com a personalidade dos diferentes genitores, mas envolvem-nas em uma descrição única e global. Esse dado deve ser questionado, em virtude da literatura já nos mostrar que pais e mães se relacionam de forma diferente com os filhos, sendo as mães mais envolvidas no suporte emocional, disciplina, cuidados básicos e tarefas escolares (Bossardi, 2011), e os pais no suporte econômico, em jogos físicos e na disciplina (Backes, 2015; Goetz \& Vieira, 2009). A relação entre fatores da personalidade e dimensões da parentalidade já foi investigada em um estudo de revisão realizado por Prinzie et al., (2009). Os autores realizaram meta-análises usando díades de pai-filho incluídas em 30 estudos. A busca foi realizada em agosto de 2008, nas bases de dados PsycINFO e ERIC e nenhum ano específico foi indicado. Como critério de inclusão, selecionou-se estudos cujos questionários incluíssem medidas de um ou mais fatores de personalidade do Big Five.

Com relação aos resultados, verificou-se que níveis mais elevados de Extroversão, Amabilidade, Conscienciosidade e Abertura e níveis mais baixos de Neuroticismo foram relacionados a mais calor (warmth) e controle comportamental, enquanto que níveis mais altos de Amabilidade e níveis mais baixos de Neuroticismo estavam mais relacionados ao suporte de autonomia dos filhos. Assim, o presente estudo pode contribuir com a atualização dessa revisão e ampliação dos resultados, na medida em que acessou outras bases de dados e teve acesso a artigos que não estavam presentes na revisão metaanalítica.

Investigar a personalidade de pais e mães e a relação dessa variável com aspectos do comportamento parental pode permitir reflexões sobre por que alguns pais e mães conseguem se envolver, brincar, cuidar, se divertir e se sentir à vontade com os filhos e outros sentem-se mais retraídos, inibidos, inseguros de fazer parte dessa interação. Destaca-se que existem diversos fatores que influenciam esse envolvimento, como as características da criança, a relação conjugal e o trabalho dos pais (Backes, 2015; Bossardi, 2011; Lamb, 1992). O que se espera do presente estudo é levantar as principais 
características paternas e maternas predominantes no exercício da parentalidade, contribuir com a prevenção de fatores de risco e o desenvolvimento de medidas de intervenção eficazes e também com a identificação de pessoas que possam ter dificuldades parentais.

Dessa forma, o propósito dessa revisão integrativa da literatura é apresentar um panorama abrangente e detalhado da produção nacional e internacional de artigos derivados de pesquisas sobre a parentalidade e a personalidade parental, com o objetivo geral de apresentar e enfatizar os aspectos relacionados a pais e mães. Temse como objetivos específicos investigar os modelos teóricos sobre personalidade; apresentar as relações já encontradas entre os cinco fatores da personalidade e o comportamento de pais e mães; realizar uma análise metodológica dos artigos encontrados e assinalar as limitações das pesquisas e lacunas na literatura. Ressalta-se que a presente revisão envolve, além da análise dos resumos, a apreciação dos artigos na íntegra, tendo em vista que nem todos os resumos disponibilizam informações sobre as escolhas metodológicas. Além disso, a leitura integral dos textos permitiu uma análise mais aprofundada dos resultados apresentados.

\section{Método}

Para a realização da busca por publicações sobre a personalidade de pais e mães e as relações entre pai, mães e filhos, primeiramente se fez a escolha dos descritores nas Terminologias da Biblioteca Virtual (BVS-Psi). Foram encontrados os descritores em inglês para personalidade e parentalidade. Assim, optou-se por "parenting" e "parental personality", cuja estratégia de busca foi "parenting" AND "parental personality". Esse último foi escolhido pois observou-se na literatura que é o termo mais utilizado para se referir à personalidade de pais e mães. Utilizou-se o operador booleano AND com vistas à localizar obras que investigassem esses dois constructos no mesmo estudo. Os termos utilizados estão na língua inglesa porque nas publicações brasileiras submete-se as palavras-chave também em inglês. Buscou-se por não restringir o período de publicação das obras.

A busca foi realizada em janeiro de 2016, nos sítios BVS-PSi, Capes Periódicos e PubMed. Como critério de inclusão optou-se por obras revisadas por pares que se referissem a aspectos da relação entre pais, mães e filho(a)s e à personalidade do pai e/ou da mãe. Não se restringiu a idade dos filhos. Foram critérios de exclusão: a) obras que não permitiam acesso online ao texto completo (ou o acesso era pago); b) estudos teóricos e de revisão. Não foram excluídas obras que tratavam da personalidade de pais e mães no mesmo estudo. 
Após a realização do levantamento da produção científica ocorreram os seguintes procedimentos: retirada do material duplicado, leitura dos títulos, resumos e seleção dos artigos relacionados ao objetivo dessa revisão; leitura integral dos artigos para apreciação das categorias de análise.

Os artigos selecionados para análise compreenderam apenas estudos empíricos com texto completo disponível em português ou em inglês e que apresentassem resultados e discussões acerca da parentalidade e da personalidade de pais e mães. Foram excluídos livros, capítulos de livros, teses, dissertações, além dos artigos teóricos e daqueles sem texto completo disponibilizado. Por fim, os artigos lidos foram organizados em uma tabela e classificados com relação a origem do estudo; ano de publicação; delineamento metodológico (método, técnica de coleta de dados, tipo do estudo, análise de dados); população estudada; referencial teórico de personalidade e principais resultados. A escolha desses critérios para análise dos documentos foi fundamentada em outros estudos de levantamentos bibliográficos (Cordazzo, Martins, Macarini, \& Vieira, 2007; Vieira et al., 2014).

\section{Resultados}

Encontrou-se um total de 137 referências, sendo 109 na Capes Periódicos, 27 do sítio PubMed e 2 da Bvs-Psi, as quais foram analisadas pela leitura dos títulos e em seguida pelos resumos. Foram excluídos 21 trabalhos duplicados. Após a leitura dos resumos, foram selecionadas 12 referências que atenderam ao critério de inclusão. Durante a leitura dos artigos, encontrou-se mais 6 estudos que se enquadravam no critério de inclusão. Dessa forma, serão analisados 18 artigos na íntegra. O passo a passo da escolha dos artigos é ilustrado no esquema abaixo. 


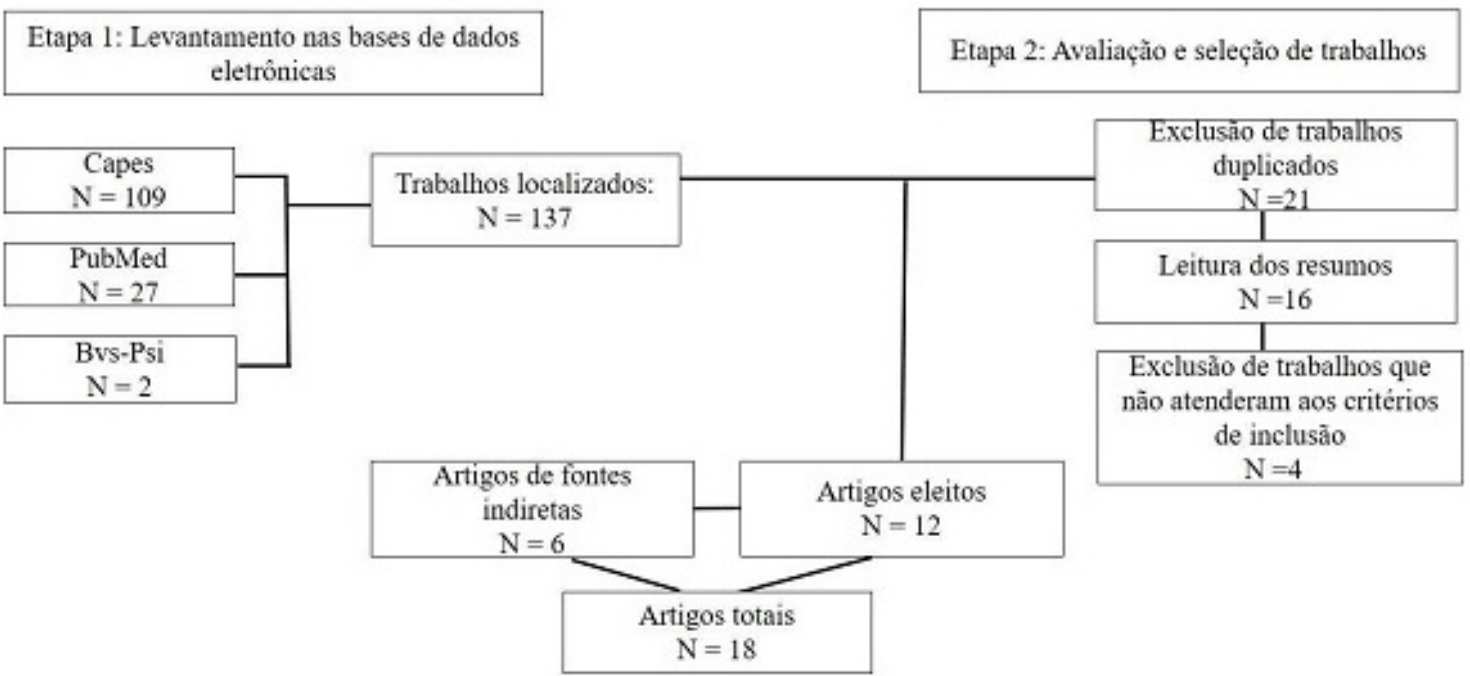

Figura 1: Esquema representativo do processo de seleção das publicações.

As obras que foram excluídas da análise por não contemplarem os critérios de inclusão se referem à outras temáticas, tais como: desempenho escolar, transição para a parentalidade, coparentalidade, divórcio, transtornos de personalidade, déficit de atenção e hiperatividade, autismo, uso de drogas, síndrome de Down, conflito na relação entre família e trabalho, entre outros.

\subsection{Origem dos documentos}

Com relação à origem dos documentos analisados, 10 eram norteamericanos (Pensilvânia, Califórnia e Canadá) e oito europeus (Holanda, Portugal, Bélgica, Finlândia). Observa-se que não há artigos nacionais sobre a temática da personalidade parental e que a prevalência dos estudos se situa em países norte-americanos e europeus. Os dados assinalam a relevância de incluir os artigos internacionais na revisão de literatura e a necessidade de produzir estudos sobre esta temática em âmbito nacional.

\subsection{Ano de publicação}

O ano de publicação das obras ficou distribuído entre os períodos de 1991 a 1998 (quatro artigos), de 1999 a 2009 (oito artigos) e de 2010 em diante (seis obras). Observa-se uma constância no número de publicações ao longo dos anos. E supõe-se que o início de publicações sobre a temática da personalidade parental tenha ocorrido após 1984, pois este foi o ano da publicação do modelo dos determinantes da parentalidade (Belsky, 1984), no qual foi salientada a importância da personalidade dos pais. 


\subsection{Delineamento metodológico}

O método mais empregado nos estudos foi o levantamento de dados (que utiliza instrumentos como questionários, escalas e/ou entrevistas para acessar o fenômeno em questão), com destaque para os questionários combinados com método de observação. A ampla maioria das pesquisas foi de natureza longitudinal e recorreu à análise quantitativa dos dados.

\begin{tabular}{ll} 
Tabela 1 & \\
$\begin{array}{l}\text { Caracterização metodológica dos artigos publicados sobre } \\
\text { personalidade e parentalidade }\end{array}$ & N \\
\hline Variável & 9 \\
\hline Método & 9 \\
\hline Levantamento de dados & 9 \\
Levantamento e Observação & 9 \\
\hline Técnica utilizada & 8 \\
\hline Questionários ou escalas & 10 \\
\hline Questionários/escalas e Observação & 18 \\
\hline Tipo de estudo & \\
\hline Transversal & \\
\hline Longitudinal & \\
\hline Análise de dados & 9 \\
\hline Quantitativa &
\end{tabular}

\subsection{População estudada}

Predominaram estudos que focaram em uma combinação de pai, mãe e filhos (11 artigos), sendo que destes, sete foram com criança e quatro com adolescente. Também houve estudos que investigaram apenas o pai e a criança (três), sendo um deles com bebês e outro com crianças pré-escolares, dois que abordaram apenas a mãe e a criança e dois que investigaram apenas o pai e a mãe.

\subsection{Referencial teórico de personalidade}

No que se refere aos modelos teóricos sobre personalidade, o modelo dos Cinco Grandes Fatores predominou na maioria dos estudos, enquanto quatro artigos utilizaram perspectivas teóricas diferentes. Essas perspectivas se referem ao modelo de personalidade proposto 
por Jackson (1976, 1980 como citado em Levy-shiff \& Israelashvili, 1988; Volling \& Belsky, 1991), o qual é dividido nas dimensões de Autonomia (indivíduos livres, que não gostam de restrições e obrigações), Autoestima (o quanto a pessoa se percebe como socialmente adequada e digna de interesse e cuidado dos outros), Orientação emocional e intelectual (sensibilidade e abertura a novas experiências) e Afeto interpessoal e afiliação (o quanto o indivíduo se preocupa com o sentimento dos outros); ao modelo de Eysenck, composto por três fatores da personalidade com polos opostos: Extroversão/Introversão, Neuroticismo/ Estabilidade e Psicoticismo/Superego (Afonseca, Martins, \& Pires, 2011); e também o modelo multidimensional proposto por Tellegen (1982 como citado em Wilson \& Durbin, 2012), composto por três dimensões e traços específicos: emocionalidade positiva (bem estar, proximidade social, realização), emocionalidade negativa (reações de estresse, alienação e agressividade) e restrição (autocontrole, convencionalismo e prevenção de danos).

\subsection{Temas investigados e principais resultados}

A fim de organizar a apresentação dos resultados das pesquisas, foram criadas categorias temáticas, conforme similaridades nos temas dos artigos. Dentro de cada categoria serão apresentados os principais resultados dos estudos, buscando articulá-los. A Tabela 2 traz os temas abarcados pelas categorias e a quantidade de estudos pertencentes a elas.

Tabela 2

Distribuição dos estudos por categoria temática

\begin{tabular}{lll}
\hline Categoria Temática & Principais Temas & Quantidade de artigos \\
\hline Personalidade e parentalidade & $\begin{array}{l}\text { Estilo parental, parentalidade diferenciada, } \\
\text { influência do contexto socioeconômico, } \\
\text { cuidados fisicos, emocionais, lúdicos, apego } \\
\text { seguro pai-filho. }\end{array}$ & 9 \\
\hline $\begin{array}{l}\text { Personalidade, parentalidade e comportamento } \\
\text { dos filhos }\end{array}$ & $\begin{array}{l}\text { Relação entre personalidade, comportamento } \\
\text { parental, comportamento de crianças e } \\
\text { adolescentes }\end{array}$ & 5 \\
\hline $\begin{array}{l}\text { Parentalidade e Personalidade influenciadas por } \\
\text { outras variáveis }\end{array}$ & $\begin{array}{l}\text { Risco demográfico, nivel socioeconômico e } \\
\text { educacional, senso de competência, humor } \\
\text { parental, stress e desafios no contexto familiar }\end{array}$ & 4 \\
\hline
\end{tabular}

\subsection{Personalidade e parentalidade}

Os artigos que fazem parte dessa categoria buscaram correlacionar traços da personalidade e aspectos relacionados à parentalidade, tais 
como: estilo parental, interação em atividades lúdicas, e relação de apego entre pai e filhos, cuidados básicos.

No que se refere à temática do estilo parental, um estudo realizado com adolescentes verificou que a combinação das características extroversão, amabilidade e estabilidade emocional pode estar relacionada a pais e mães que tendem a exercer um estilo autoritativo, caracterizado por demonstração de afeto, carinho, controle e disciplina (Baumrind, 1996). Extroversão e amabilidade estariam ligadas à capacidade de os pais darem suporte emocional aos filhos, e a estabilidade emocional com baixo controle e disciplina. Os resultados desse estudo sublinham a relação entre extroversão e parentalidade, evidenciando a importância dessa característica da personalidade para aspectos afetivos da parentalidade (Huver, Otten, de Vries, \& Engels, 2010).

A relação da extroversão com aspectos emocionais e de cuidado também foi evidenciada em outro estudo sobre estilos parentais, realizado com pais, mães e crianças (Pulkkinen \& Metsapelto, 2003). As figuras parentais com níveis altos em extroversão e níveis altos a moderado em abertura à experiência também demonstraram um estilo autoritativo. Essas características podem estar relacionadas a pais e mães que são sociáveis, alegres, afetuosos, curiosos e flexíveis, capazes tanto de dar suporte aos filhos quanto de colocar limites necessários. $O$ estilo parental autoritário foi presente em pais e mães com níveis baixos em abertura à experiência e em extroversão, o que pode estar associado a uma dificuldade desses pais em serem carinhosos, em demonstrar afeto e suporte emocional, estimular experiências positivas e em ser flexível a novas experiências.

O estilo permissivo, que se caracteriza por pouca imposição de limites, regras e restrições, mas também por demonstração de afeto e cuidado aos filhos (Baumrind, 1996) esteve presente em pais e mães que apresentaram níveis elevados em neuroticismo, extroversão e abertura (Pulkkinen \& Metsapelto, 2003). Esses traços podem estar relacionados a pais e mães que dão suporte emocional, que são carinhosos, porém muito flexíveis e despreocupados. Nesse estudo, a característica conscienciosidade não foi significativa para nenhum dos estilos parentais, porém exerceu influência diferente entre os pais e mães. Outro estudo verificou que pai alto em conscienciosidade tende a dar suporte, ser sensível e menos assertivo, enquanto que mães fortes nesse traço descreveram sua relação com os filhos adolescentes com muito envolvimento e comunicação, além de demonstraram mais facilidade em colocar limites na educação (Huver et al., 2010).

A capacidade dos pais em estimular e participar de atividades lúdicas também esteve relacionada a traços de personalidade. Esse aspecto foi investigado apenas entre os pais. Um dos estudos revelou que 
pais cuidadores e lúdicos tendem a ser menos neuróticos, mais educados e possuem melhor prestígio ocupacional (Jain, Belsky, \& Crnic, 1996). Outra pesquisa apontou que pais com afeto interpessoal, os quais demonstram consideração pelo sentimento da criança, também se envolvem em atividades lúdicas (Volling \& Belsky, 1991).

Outra característica associada às atividades lúdicas é a extroversão, que se refere a pessoas sociáveis, enérgicas, alegres, impulsivas. Um estudo feito apenas com o pai e a criança encontrou que pais de crianças seguras são mais extrovertidos e amáveis que pais de crianças inseguras (Jain et al., 2006). Extroversão também foi presente em pais que expressam sentimentos na interação com os filhos (Belsky, Crnic, \& Woodworth, 1995). Assim, as características de extroversão e abertura à experiência parecem estar relacionadas a pais que estimulam o comportamento social, que se envolvem em brincadeiras e jogos lúdicos e que demonstram sensibilidade e sentimentos aos filhos.

No entanto, parece haver divergências entre os resultados acerca da influência da extroversão. Outro estudo apontou que apesar dessa característica ter sido forte em mães que se sentiam envolvidas com os filhos, com relação aos pais, a introversão foi mais predominante, aparecendo relacionada com comportamentos de interação centrados na criança (Metsapelto \& Pulkkinen, 2005). Isso pode ser explicado em parte pela baixa assertividade e em parte pelo firme controle dos impulsos, que são atributos da introversão. Nesse estudo, pais e crianças tinham que resolver palavras cruzadas, tarefa que exigiu baixa assertividade e alto controle de impulso por parte do pai, de modo a permitir liberdade à criança para explorar a construção das palavras. Pais extrovertidos se comportaram de uma forma mais dominante e com poder assertivo e foram, assim, considerados menos aptos em compartilhar sentimentos e experiências com os filhos, em demonstrar aceitação e capacidade de resposta às necessidades e opiniões da criança.

No que se refere à participação dos pais nos cuidados, um estudo revelou que pais altos em neuroticismo tendem a prestar cuidados ao bebê, além de demonstrarem maior preocupação com as consultas pré-natais (Afonseca, Martins, \& Pires, 2011). Parece que essa característica da personalidade está relacionada a pais que tendem a ser inseguros e/ou preocupados se algo está errado com a criança, e por isso, podem ser inibidos e se sentir desconfortáveis em interagir com elas. No entanto, o fato de esses pais prestarem cuidados ao bebê vai de encontro ao resultado encontrado por Pulkkinen e Metsapelto (2003), que verificaram que pais e mães de personalidade marcada por neuroticismo demonstram uma parentalidade caracterizada por insegurança, inibição e desconforto na interação com as crianças. 


\subsection{Personalidade, parentalidade e comportamento do(a)s filho(a)s}

Os aspectos emocionais que compõem a personalidade exercem influência nas práticas parentais, na maneira como os pais se relacionam com os filhos e no próprio comportamento destes. Fazem parte dessa categoria artigos que investigaram como a personalidade e/ou o comportamento dos filhos podem moldar o comportamento parental, e como a personalidade dos pais pode moldar 0 comportamento dos filhos.

A extroversão e a amabilidade se mostraram significativas em modelar dois tipos de comportamento parental: reativo e amoroso. Embora tenham conotações diferentes, essas características da personalidade se referem a comportamentos de interações sociais. Verificou-se que enquanto a extroversão adolescente (indivíduos enérgicos, sociáveis, impulsivos) tendia a eliciar mais comportamentos reativos dos pais, a amabilidade e a estabilidade emocional de ambos promoviam uma relação mais calorosa e amorosa (Haan, Deković, \& Prinzie, 2012).

Contudo, dois estudos verificaram que a personalidade parental não é capaz de prever o comportamento dos filhos, mas que seu efeito pode ser mediado pelas práticas parentais (Van Aken et al., 2007).

Observou-se que a instabilidade emocional materna pode prever comportamentos agressivos na criança quando mediada por pouco suporte materno dado aos filhos. Ou seja, quando a mãe apresenta muita instabilidade emocional e ainda fornece pouco suporte, esses fatores podem eliciar comportamentos agressivos nos filhos. Enquanto que para os pais a própria instabilidade emocional tende a gerar comportamentos agressivos dos filhos. Isso pode ser devido à preferência das crianças em procurar mais as mães para confortá-las e acalmá-las (Lamb, 1992).

A capacidade dos pais em colocar limites na educação dos filhos apareceu relacionada à dimensão conscienciosidade (Oliver, Guerin, \& Coffman, 2009). Pais e mães altos nessa dimensão possuem maior facilidade em delimitar limites aos filhos os quais, por sua vez, tendem a apresentar menos problemas de comportamento externalizante, agressividade e dificuldades de atenção.

\subsection{Personalidade e parentalidade mediadas por uma terceira variável}

Esta categoria é composta por quatro estudos que investigaram o envolvimento de uma terceira variável na relação entre personalidade e parentalidade. Um deles examinou a personalidade como um moderador do impacto do risco demográfico sobre a parentalidade (Kochanska, Aksan, Penney, \& Boldt, 2007). Esse risco estava 
relacionado a experiências instáveis e infelizes durante a infância. Verificou-se que a personalidade dos pais moderou o impacto do risco demográfico sobre a parentalidade: pais ricos em neuroticismo e mães com níveis baixos em extroversão, que tiveram experiências instáveis durante a infância manifestaram mais comportamentos de afirmação de poder, enquanto que não houve nenhuma ligação com o risco para os pais e mães que recordaram experiência felizes da infância.

Além disso, os aspectos socioeconômicos e o trabalho dos pais podem mediar a relação entre a personalidade e a participação dos pais nas tarefas familiares. Um estudo verificou que o pai com autoestima e sensível aos sentimentos das pessoas tende a ser responsável e a se envolver com a criança apenas em famílias nas quais um genitor trabalha. Já em famílias nas quais ambos os pais trabalham isso tende a não ocorrer devido a maior divisão de tarefas e aos conflitos provenientes da relação entre família e trabalho (Volling \& Belsky, 1991).

Também foi investigado o papel mediador do senso de competência na relação entre as cinco dimensões da personalidade e duas dimensões da parentalidade: superreatividade (overreactivity) e calorosidade (warmth). O senso de competência se refere à crença de autoeficácia dos pais em se sentirem efetivamente capazes de gerenciar as tarefas parentais. Quanto mais forte foi o senso de competência de pais e mães, e quanto mais extrovertidos e amáveis eles foram, menos comportamentos de superreatividade foram eliciados e mais envolvimento e afeto foram demonstrados na relação com os filhos. Essa associação foi semelhante para pais e mães (Haan, Prinzie, \& Deković, 2009).

O humor parental (positivo e negativo) e os aborrecimentos diários também foram investigados como aspectos mediadores da relação entre personalidade e parentalidade. Os resultados apontaram que a extroversão exerceu maior influência sobre a paternidade, enquanto que a amabilidade exerceu maior influência sobre a maternidade. Essa diferença pode estar relacionada aos diferentes papeis exercidos por pais e mães. O fato de os pais se envolverem mais em jogos e brincadeiras seria reforçado pela característica da extroversão, pois essa se refere a indivíduos ativos, sociáveis, divertidos e que tendem a expressar mais afeto positivo para a criança. Já no que se refere às mães, a dimensão amabilidade - que descreve pessoas confiáveis, sensíveis e compassivas - estaria relacionada à tendência das mães em se dedicarem mais aos cuidados, a confortar os filhos e a serem carinhosas e responsivas com eles. $E$, por fim, o neuroticismo mostrou-se como o preditor da parentalidade de ambos os pais, influenciando $o$ humor, os aborrecimentos diários e os comportamentos parentais (Belsky, Crnic, \& Woodworth, 1995). 


\section{Discussão}

Foi possível constatar, a partir dos resultados obtidos, a existência de publicações exclusivamente internacionais concernentes às interrelações entre personalidade parental e parentalidade. Além disso, como evidenciado na literatura, observa-se uma tendência a se investigar apenas a personalidade materna, visto que apenas três obras focaram exclusivamente as características individuais do pai. Isso pode ser devido a um contexto em que é recente a temática sobre a importância do pai no desenvolvimento infantil.

Em termos metodológicos, constatou-se o predomínio da abordagem quantitativa. Em consequência dessa escolha epistemológica, foi evidenciada a preferência pelo levantamento de dados, com abordagem multimétodos, utilizando questionários e/ou entrevistas combinados com observação. Com relação à população estudada, nota-se que há uma tendência internacional em investigar a relação entre os integrantes da família nuclear, especialmente em estudos de observação.

No que se refere à perspectiva teórica utilizada nos estudos, verificou-se a predominância do modelo ecológico dos determinantes da parentalidade (Belsky, 1984), o qual sugere a inter-relação do comportamento parental com diferentes fatores: personalidade e os recursos psicológicos dos pais, características da criança e fontes de stress e de apoio do contexto no qual a relação pais-criança está inserida. Foi possível verificar a articulação de alguns desses fatores no delineamento dos estudos, como a relação entre personalidade parental e comportamento da criança; personalidade, comportamento parental e trabalho dos pais e também a influência do contexto social que pode envolver a condição socioeconômica da família, fatores de risco e a vulnerabilidade social.

Dessa forma, essa perspectiva permite uma compreensão ampla acerca da parentalidade, além de fundamentar a importância de se investigar as características individuais dos pais e a contribuição que elas podem exercer nas práticas parentais. Além disso, no que diz respeito ao quadro teórico utilizado para se investigar e discutir a personalidade, predominou o modelo dos Cinco Grandes Fatores da Personalidade (Big Five), o qual é confirmado pela literatura como o modelo cientificamente mais aceito e consistente (McCrae \& Costa, 1999; McCrae \& John, 1992).

No que diz respeito às características e comportamentos específicos das figuras parentais observou-se que a maioria das pesquisas analisadas tende a englobar pais e mães nos mesmos resultados, sem diferenciá-los. Com o intuito de propiciar essa diferenciação, atentou-se mais para os estudos que investigaram só o pai ou só a mãe. No que se refere à figura paterna, verificou-se que os traços de amabilidade e extroversão estão ligados a uma relação de apego 
seguro entre pai e criança, mas também pais introvertidos se mostraram envolvidos e responsivos, organizando o próprio comportamento a partir da perspectiva da criança (Belsky, 1996).

As características de amabilidade e extroversão refletiram pais amáveis, sociáveis, afetuosos e dominantes, que se envolvem com a criança proporcionando a ela uma relação segura (Haan, Dekovic, \& Prinzie, 2012) A extroversão e a abertura foram relacionadas com o envolvimento em atividades lúdicas (Belsky et al., 1995). A introversão paterna refletiu comportamentos de baixa assertividade e controle de impulsos, os quais por sua vez estavam relacionados ao respeito às opiniões da criança, liberdade para exploração e incentivo à sua autonomia (Metsapelto \& Pulkkinen, 2005).

Com relação à mãe, as características de amabilidade e extroversão se relacionaram a uma parentalidade calorosa e envolvida (Haan, Dekovic, \& Prinzie, 2012; Metsapelto \& Pulkkinen, 2005). A instabilidade emocional (neuroticismo) foi influente de forma semelhante para ambas as figuras parentais: quando combinado com outras características, pode tanto propiciar uma parentalidade permissiva, com pouco controle e disciplina (Belsky et al., 1995; Prinzie et al., 2009) e também uma parentalidade autoritária, rígida e coercitiva (Pulkkinen \& Metsapelto, 2003). Com relação às mães, o neuroticismo apareceu relacionado com comportamentos de afirmação de poder, com pouco suporte proporcionado aos filhos e também com a eliciação de comportamento agressivo desses (Kochanska, Aksan, Penney, \& Boldt, 2007; Kochanska, Kim, \& Nordling, 2012). Essa combinação com outras características também ocorreu com a dimensão abertura à experiência, que parece mediar a participação dos pais em atividades lúdicas e permitir uma parentalidade mais flexível (Volling \& Belsky, 1991). Pais e mães conscienciosos se mostraram emocionalmente envolvidos e aptos a colocar limites na criação dos filhos (Oliver et al., 2009).

Dessa forma, com o propósito de tornar os resultados mais claros e objetivos, pretendeu-se resumir as relações encontradas entre os traços de personalidade e os comportamentos de pais e mães por meio de um quadro esquemático que articulasse a dimensão Atividades Parentais e suas subdimensões, propostas por Hoghughi (2004) e as características de personalidade de pais e mães. Optouse apenas por essa dimensão da parentalidade, pois ela tende a englobar somente os comportamentos parentais em interação direta com a criança, os quais visam o seu desenvolvimento. A Tabela 3 apresenta, esquematicamente, a articulação entre as subdimensões cuidados físicos, cuidados emocionais, controle e disciplina, cuidado social e atividades lúdicas - e as características da personalidade. 
Tabela 3

Quadro esquemático dos resultados sobre personalidade e atividades parentais

\begin{tabular}{|c|c|}
\hline Cuidados Físicos & Controle e Disciplina \\
\hline $\begin{array}{l}\text { Extroversão: Pai e mãe extrovertidos participam dos cuidados } \\
\text { básicos } \\
\text { Alto Neuroticimo: Pai alto em neuroticismo se preocupa com as } \\
\text { consultas pré-natais } \\
\text { Baixo Neuroticismo: pai baixo em neuroticismo, sensivel e com } \\
\text { realização profissional se envolve nos cuidados físicos } \\
\text { Amabilidade: Mães altas em amabilidade se envolvem nos } \\
\text { cuidados fisicos e são calorosas. }\end{array}$ & $\begin{array}{l}\text { Baixa Abertura e Baixa Extroversão: pais e mães tendem a ter } \\
\text { um estilo autoritário (exercem controle e autoridade) } \\
\text { Alto Neuroticismo, Extroversão e Abertura: pais e mães tendem } \\
\text { a ter um estilo permissivo (há afeto e cuidado, porém falta de } \\
\text { regras e padrōes) } \\
\text { Alto Neuroticismo para o pai: afirmação de poder } \\
\text { Baixa Extroversão para a mãe: afirmação de poder } \\
\text { Conscienciosidade: capacidade de impor limites na educação } \\
\text { dos fillhos. }\end{array}$ \\
\hline Cuidados Emocionais & Cuidado social e atividades lúdicas \\
\hline $\begin{array}{l}\text { Extroversão, Amabilidade e Estabilidade emocional: pai e mãe } \\
\text { tendem a ter um estilo autoritativo (são afetuosos e dão limites) } \\
\text { Extroversão e Abertura à Experiência: Pai e mãe extrovertidos e } \\
\text { abertos à experiência tendem a dar suporte emocional, ser } \\
\text { calorosos e afetuosos } \\
\text { Extroversão: pai tende a promover apego seguro na relação } \\
\text { com a criança } \\
\text { Amabilidade e Estabilidade emocional: Mãe tendem a } \\
\text { estabelecer uma relação amorosa e calorosa com os filhos } \\
\text { Alto Neuroticismo: afeta o humor de pais e mães - pouco } \\
\text { envolvimento emocional }\end{array}$ & $\begin{array}{l}\text { Baixo Neuroticismo e realização profissional: pais lúdicos. } \\
\text { Extroversão: pai interage com os filhos } \mathrm{em} \text { brincadeiras } \\
\text { (individuos ativos, sociáveis, divertidos) } \\
\text { Afeto interpessoal: pai é sensivel ao sentimento da criança, se } \\
\text { envolvendo em atividades lúdicas e interagindo de acordo com } \\
\text { a perspectiva da criança }\end{array}$ \\
\hline
\end{tabular}

No que concerne à subdimensão cuidados físicos, foram incluídas as relações entre as características de personalidade e/ou a combinação entre elas e os tipos de cuidados físicos, que podem envolver a proteção, a higiene, a ida a consultas pré-natais, entre outros. Os cuidados emocionais compreendem os aspectos encontrados nos estudos referentes a afeto, calor, amorosidade e apego seguro, por estarem atrelados a uma parentalidade calorosa, envolvida e também ao desenvolvimento emocional dos filhos. A subdimensão controle e disciplina engloba resultados alusivos ao controle, autoridade, afirmação de poder e imposição de limites na educação. E, por fim, a subdimensão cuidado social integra comportamentos que visem tornar a criança socialmente competente, como as atividades lúdicas e brincadeiras.

As limitações apontadas pelas pesquisas envolvem, principalmente, a impossibilidade dos estudos transversais em estabelecer relações causais entre personalidade e outras variáveis, devido à mutabilidade dos traços da personalidade, que sofrem transformações ao longo do tempo. Dessa forma, os estudos sugerem a investigação da temporalidade e variação da personalidade por meio de estudos longitudinais.

A maioria dos estudos analisados utiliza o termo personalidade parental (parental personality), tanto na introdução, quanto nos resultados e também não diferenciam o gênero da criança nos estudos de observação. Isso implicou, em alguns estudos, a uma não diferenciação da parentalidade com relação ao gênero da figura 
parental e filial, o que leva a alguns questionamentos, já que pais e mães e mães se relacionam de forma diferentes com os filhos e filhas (Backes, 2015; Bossardi, 2011; Paquette \& Dumont, 2013).

As relações estabelecidas entre personalidade e comportamento parental não podem ser compreendidas de forma tão direta. Inúmeros fatores permeiam essa relação, como o senso de competência e eficácia dos pais (Haan et al., 2009), o risco demográfico (Harris, Furstenberg, \& Marmer, 1998), o comportamento e a personalidade dos filhos (Haan, Dekovic, \& Prinzie, 2012; Prinzie, Onghena, Hellinckx, \& Grietens, 2005; Van Aken et al., 2007). Nota-se que personalidade e parentalidade são conceitos muito mais complexos que a forma como eles têm sido tratados. Assim, o exame de dimensões é apenas uma estratégia informativa, que oferece uma visão sobre a parentalidade e a personalidade em um nível básico e estruturado (Huver et al., 2010).

\section{Considerações finais}

O objetivo do presente estudo foi verificar, por meio de uma revisão integrativa, as relações estabelecidas entre as características de personalidade de pais e mães e a parentalidade. Verificou-se que as características de personalidade exercem influência sobre a parentalidade quando combinadas entre si. De maneira geral, podese indicar que amabilidade está mais relacionada a pais e mães calorosos, cuidadosos e envolvidos; a extroversão a atividades lúdicas, descontraídas; a introversão a pais envolvidos e que respeitam as opiniões e perspectivas da criança; a conscienciosidade à habilidade de impor limites e disciplina; a abertura à experiência à capacidade de ser flexível, e quando combinada com outros traços, pode estar associada a certa permissividade; e por fim, o neuroticismo pode estar relacionado tanto à rigidez, insegurança e também à negligência ou ao envolvimento nos cuidados básicos.

A análise realizada indica que há uma tendência de as pesquisas não diferenciarem as práticas parentais de acordo com as características individuais maternas e paternas, englobando-as em dimensões gerais da parentalidade, como calorosidade, restrição, coerção, entre outros. Dessa forma, aponta-se a necessidade de se focar nas diferenças entre as figuras parentais, tanto de personalidade quanto de parentalidade, a fim de verificar em que medida as discrepâncias de personalidade estão relacionadas com as diferenças de parentalidade entre eles. Aponta-se a relevância da utilização de estudos longitudinais e observacionais, que investiguem o fenômeno de modo direto e em situações específicas, testando relações e repercussões entre diferentes variáveis. Sugere-se que estes estudos de observação atentem para as características da criança e para a 
maneira diferenciada com que pais e mães interagem com meninos e meninas.

Recomenda-se que investigações futuras explorem a personalidade sob uma perspectiva bioecológica, abarcando vários determinantes da parentalidade. Esses determinantes podem ser os aspectos sociais, econômicos, educacionais, emocionais e transgeracionais, em virtude de eles promoverem repercussões sobre a forma como pais e mães executam as práticas parentais e se relacionam com filhos e filhas. Salienta-se a necessidade de ampliar os estudos nas diversas configurações familiares, especialmente naquelas em que o pai está presente fisicamente e/ou emocionalmente, e investigar com profundidade os fatores que podem influenciar a parentalidade. Por fim, os resultados desse estudo podem servir de estímulo para futuras pesquisas e também intervenções que atentem para a identificação da personalidade como um fator que pode colocar em risco a parentalidade e o desenvolvimento saudável da família e dos filhos.

\section{Referências}

Afonseca, S., Martins, A., \& Pires, V. (2011). Influência da personalidade do pai na participação da prestação de cuidados ao bebê. Revista inFormação, 15(15), 14-38.

Backes, M. S. (2015). A relação entre o envolvimento paterno e a abertura ao mundo em pais de crianças entre quatro a seis anos (Dissertação de Mestrado), Universidade Federal de Santa Catarina, Florianópolis, SC, Brasil.

Bandeira, M. S., Goetz, E. R., Vieira, M. L., \& Pontes, F. A. R. (2005). $O$ cuidado parental e o papel do pai no contexto familiar. In $F$. A. R. Pontes (Ed.), Temas pertinentes à construção da Psicologia Contemporânea. (pp. 191-230). Pará: Editora da Universidade do Pará.

Baumrind, D. (1996). Effects of authoritative parental control on child behavior. Child Development, 37, 887-907.

Belsky, J. (1984). The determinants of parenting: a process model. Child Development, 55(1), 183-96.

Belsky, J., \& Jaffee, S. R. (2006). The multiple determinants of parenting. In D. Cicchetti \& D. Cohen (Eds.), Developmental Psychopathology (2nd ed., pp. 38-77). New York: Wiley.

Belsky, J., Crnic, K., \& Woodworth, S. (1995). Personality and parenting: exploring the mediating role of transient mood and daily hassles. J ournal of Personality, 63(4), 905-929.

Bossardi, C. N. (2011). Relação do engajamento parental e relacionamento conjugal no investimento com os filhos. 
Dissertação de Mestrado em Psicologia, Universidade Federal de Santa Catarina, Florianópolis, SC, Brasil.

Bronfenbrenner, U. (1979). Contexts of child rearing: Problems and prospects. American Psychologist, 34(10), 844-850. http://doi.org/10.1037/0003-066X.34.10.844

Caspi, A., Roberts, B. W., \& Shiner, R. L. (2005). Personality development: stability and change. Annual Review of Psychology, 56, 453-484. http://doi.org/10.1146/annurev.psych.55.090902.141913

Cordazzo, S. T. D., Martins, G. D. F., Macarini, S. M., \& Vieira, M. L. (2007). Perspectivas no estudo do brincar: um levantamento bibliográfico. Aletheia, 26(2003), 122-136.

DeYoung, C. G., Quilty, L. C., \& Peterson, J. B. (2007). Between facets and domains: 10 aspects of the Big Five. Journal of Personality and Social Psychology, 93(5), 880-896. http://doi.org/10.1037/0022-3514.93.5.880

Goetz, E. R., \& Vieira, M. L. (2009). Percepções dos filhos sobre aspectos reais e ideais do cuidado parental. Estudos de Psicologia (Campinas), 26(2), 195-203. http://doi.org/10.1590/S0103-166X2009000200007

Haan, A. D. De, Dekovic, M., \& Prinzie, (2012). Longitudinal Impact of Parental and Adolescent Personality on Parenting. Journal of Personality and Social Psychology, 102(1), 189-199. http://doi.org/10.1037/a0025254

Haan, A. D., Prinzie, P., \& Deković, M. (2009). Mothers' and fathers' personality and parenting: the mediating role of sense of competence. Developmental Psychology, 45(6), 1695-1707. http://doi.org/10.1037/a0016121

Harris, K. M., Furstenberg, F. F., \& Marmer, J. K. (1998). Paternal involvement with adolescents in intact families: the influence of fathers over the life course. Demography, 35(2), 201-216. http://doi.org/10.2307/3004052

Hendricks, J. W., \& Payne, S. C. (2007). Beyond the Big Five: Leader goal orientation as a predictor of leadership effectiveness. Human Performance, 20(4), 317-343. http://doi.org/10.1080/08959280701521983

Hoghughi, M. S. (2004). Parenting: an introduction. In M. S. Hoghughi \& N. Long (Eds.), Handbook of Parenting Theory and Research for Practice (pp. 1-18). Londres: Sage.

Huver, R. M. E., Otten, R., de Vries, H., \& Engels, R. C. M. E. (2010). Personality and parenting style in parents of adolescents. Journal of Adolescence, 33(3), 395-402. http://doi.org/10.1016/j.adolescence.2009.07.012

Jain, A., Belsky, J., \& Crnic, K. (1996). Beyond fathering behaviors: Types of dads. Journal of Family Psychology, 10(4), 431-442. http://doi.org/10.1037/0893-3200.10.4.431 
John, O. P., \& Srivastava, S. (1999). The Big-Five Trait Taxonomy: History, Measurement, and Theoretical Perspectives. In Handbook of personality: Theory and research (2nd ed., pp. 102-138). New York: Guilford Press.

Kochanska, G., Aksan, N., Penney, S. J., \& Boldt, L. J. (2007). Parental personality as an inner resource that moderates the impact of ecological adversity on parenting. Journal of Personality and Social Psychology, 92(1), 136-150. http://doi.org/10.1037/0022-3514.92.1.136

Kochanska, G., Kim, S., \& Nordling, J. K. (2012). Challenging circumstances moderate the links between mothers' personality traits and their parenting in low-income families with young children. Journal of Personality and Social Psychology, 103(6), 1040-1049. http://doi.org/10.1037/a0030386

Lamb, M. E. (1992). O papel do pai em mudança. Análise Psicológica, $1,19-34$.

Levy-shiff, R., \& Israelashvili, R. (1988). Antecedents of fathering: Some further exploration. Developmental Psychology, 24(3), 434-440.

McCrae, R. R., \& Costa. (1999). The five-factor theory of personality. In O. P. John, R. W. Robins, \& L. A. Pervin (Eds.), Handbook of personality: Theory and research (3rd ed., pp. 159-174). New York: The Guilford Press.

McCrae, R. R., \& John, O. P. (1992). An introduction to the five-factor model and its applications. Journal of Personality, 60(2), 175215. http://doi.org/10.1111/j.1467-6494.1992.tb00970.x

Metsäpelto, R., \& Pulkkinen, L. (2005). The moderating effect of extraversion on the relation between self-reported and observed parenting. Applied Developmental Psychology, 26, 371-384. http://doi.org/10.1016/j.appdev.2005.04.005

Metsäpelto, R.-L. (2003). Individual differences in parenting: The five-factor model of personality as an explanatory framework. Dissertação de Mestrado, Universidade de Jyväskylä, Finlândia.

Morse, M. K. (2010). The determinants and consequences of empathic parenting: Testing an expansion of Belsky's model of parenting using SEM. (Tese de Doutorado). Universidade North Texas, Texas, Estados Unidos.

Natividade, J. C., \& Hutz, C. S. (2015). Escala Reduzida de Descritores dos Cinco Fatores de Personalidade: Prós e Contras. Psico, 46(1), 79-89.

Oliver, P. H., Guerin, D. W., \& Coffman, J. K. (2009). Big five parental personality traits, parenting behaviors, and adolescent behavior problems: A mediation model. Personality and Individual Differences, 47(6), 631-636. http://doi.org/10.1016/j.paid.2009.05.026 
Paquette, D., \& Dumont, C. (2013). The father-child activation relationship, sex differences, and attachment disorganization in toddlerhood. Child Development Reseatch, 2013, 1-9. http://doi.org/10.1155/2013/102860

Prinzie, P., Onghena, P., Hellinckx, W., \& Grietens, H. (2005). Direct and indirect relationships between parental personality and externalising behaviour: The role of negative parenting. Psychologica Belgica, 45(2), 123-145.

Prinzie, P., Stams, G. J. J. M., Deković, M., Reijntjes, A. H. A., \& Belsky, J. (2009). The relations between parents' Big Five personality factors and parenting: a meta-analytic review. Journal of Personality and Social Psychology, 97(2), 351-362. http://doi.org/10.1037/a0015823

Pulkkinen, L., \& Metsapelto, R. (2003). Personality traits and parenting: Neuroticism, extraversion, and openness to experience as discriminative factors. European Journal of Personality, 17, 59-78.

Roberts, B. W., Kuncel, N. R., Shiner, R., Caspi, A., \& Goldberg, L. R. (2007). The power of personality. Perspectives on Psychological Science, 2(4), 313-345. http://doi.org/10.1111/j.17456916.2007.00047.x

Silva, M. da R., \& Piccinini, C. A. (2007). Sentimentos sobre a paternidade e o envolvimento: um estudo qualitativo. Estudos de Psicologia, 24(4), 561-574.

Staudt, A. C. P., \& Wagner, A. (2008). Paternidade em tempos de mudança. Psicologia: Teoria e Prática, 10(1), 174-185.

Van Aken, C., Junger, M., Verhoeven, M., Van Aken, M. A. G., Dekovic, M., \& Denissen, J. J. A. (2007). Parental personality, parenting and toddlers' externalising behaviours. Sex Roles, 29(4), 137-152. http://doi.org/10.1002/per

Vieira, M. L., Bossardi, C. N., Gomes, L. B., Bolze, S. D. A., Crepaldi, M. A., \& Piccinini, C. A. (2014). Paternidade no Brasil: revisão sistemática de artigos empíricos. Arquivos Brasileiros de Psicologia, 66(2), 36-52.

Volling, B. L., \& Belsky, J. (1991). Multiple determinants of father involvement during Infancy in dual-earner and single-earner families. Journal of Marriage, 53, 461-474.

Wagner, A., Predebon, J., Mosmann, C., \& Verza, F. (2005). Compartilhar tarefas? Papéis e funções de pai e mãe na família contemporânea. Psicologia: Teoria e Pesquisa, 21(2), 181-186.

Wilson, S., \& Durbin, C. E. (2012). Dyadic parent-child interaction during early childhood: Contributions of parental and child personality traits. Journal of Personality, 80(5), 1313-1338. http://doi.org/10.1111/j.1467-6494.2012.00789.x 


\section{Endereço para correspondência}

Maria Luiza I usten da Silva

Universidade Federal de Santa Catarina

Programa de Pós-Graduação em Psicologia

Campus Universitário, Trindade, CEP 88040-500, Florianópolis - SC, Brasil

Endereço eletrônico: marialuiza.iusten@gmail.com

\section{Mauro Luís Vieira}

Universidade Federal de Santa Catarina

Programa de Pós-Graduação em Psicologia

Campus Universitário, Trindade, CEP 88040-500, Florianópolis - SC, Brasil

Endereço eletrônico: maurolvieira@gmail.com

Recebido em: 07/03/2016

Reformulado em: 18/07/2017

Aceito em: 02/08/2017

\section{Notas}

* Mestre em Psicologia pelo Programa de Pós-Graduação em Psicologia da Universidade Federal de Santa Catarina.

** Doutor em Psicologia pela Universidade de São Paulo, professor do Departamento de Psicologia da Universidade Federal de Santa Catarina.

Apoio financeiro: CAPES - bolsa de mestrado concedida para primeira autora; CNPq - bolsa de produtividade para o segundo autor.

Este artigo de revista Estudos e Pesquisas em Psicologia é licenciado sob uma Licença Creative Commons Atribuição-Não Comercial 3.0 Não Adaptada. 